\title{
The Effect of Global Citizenship Education on The Psycho-social Health of Adolescents
}

\author{
Moonhyuo Jo1), Misook $\mathrm{Cho}^{2}$ )
}

\begin{abstract}
Based on prior studies that a high level of psycho-social health of adolescents has a significant relationship with healthy eating habits and the promotion of personal physical activity, this study examines whether the Global Citizenship Education (GCE) has a positive effect on various psycho-social indicators of adolescents. For this purpose, this study performed repeated measurements by split-plot of the factors that can have an effect as mediator variables while controlling the experience of volunteer work and completion of courses related to service. The effect of GCE, the independent variable, was performed by within-subject analysis under controlling the mediator variables by comparison between before and after points of view. Through between-subject analysis, a significance test was attempted through comparative analysis of differences between the levels of specific factors. This study verified whether the within-subject factor or GCE, the treatment effect affects the psycho-social health regardless of the level of a specific variable (main effect) and whether there is an interaction effect between treatment factor and insertion factor. In addition, if sphericity assumption is not met, this study tried to analyze the within-subject effects through well-known Greenhouse-Geisser verification method. As a result, in terms of the analysis of the effects within the participants of GCE, the effects of participating in GCE were significant in self-efficacy (.001), stress management (.021), and rest (0.13). In addition, in relation to volunteering experience, the effects between the GCE participants showed a significant difference in all of the variables of self-efficacy (.046), stress management (.002), personal relations (.000), and health care (.045), which confirmed that GCE has a positive effect on the psycho-social health promotion indicators of adolescents.
\end{abstract}

Keyword: Adolescent, Global Citizenship Education(GCE), Psycho-Social Health Promoting Life Style, Sustainable Development Goals(SDGs), Social Welfare

\section{Purpose of Study}

Adolescence is generally the healthiest period in life cycle and disease morbidity rate is also low. In particular, health-promoting behaviors during this period are influenced by the developmental resources of adolescents[1], and variables related to the health of adolescents are reported to include gender, positive mental health[2], social support, self-esteem[3] and internal locus of control of health [4].

Received(July 25, 2018), Review Result(1st: August 3, 2018, 2nd: September 3, 2018), Accepted(September 10, 2018)

1) (Researcher) The Secretary General, Korean Institute of Glocal Social Contribution(KIGSC)

2) (Professor, Corresponding Author) 01795 Department of Social Welfare, Sahmyook University, Hwarangro 815, Nowon-gu, Seoul, South Korea.

email: joms@syu.ac.kr 
Beyond the past point of view that simply defined adolescence as a period of 'sturm and drang', debates over their developmental resources started and a variety of studies[5] have been conducted which showed that the positive resources of adolescents can be important factors in the health trajectory from adolescence to early adulthood. Interestingly, in the case of Eyler and Giles[6], while explaining the theoretical relevance between intellectual and emotional performance, adolescents who experience GCE face the challenge of reconfirming or readjusting their own perspectives by making contact with various people with different perspectives, which increases their understanding of other peoples' positions through reflection and expands their scope of possibilities to create a sense of psycho-social well-being[6].

In summary, this means that psycho-social health is linked to individual's evaluation of their own life in a multidisciplinary area that integrates experience, achievement, quality of relationship, and function[4], so the impact of GCE on the psycho-social health of adolescents is very important. In addition, the GCE experience activities which aim to 'achieve a sustainable coexistence where people live together' provides a positive perception of yourself by building trust in humans along with psycho-social well-being, which will remain as an internal working model to infer the logical structure that can affect an individual's psycho-social health. Therefore, research on this issue is very urgent given the lack of studies on the health of adolescents in Korea, in terms of helping to foster correct health behaviors and habits during adolescence will have a long-term effect on lifelong health promotion behavior and more positive health outcomes, the purpose of this study is to present growth-oriented and integrated social welfare implications through the empirical verification of the effects of global citizen education on the psycho-social health of adolescents.

\section{Theoretical Background}

\subsection{GCE and Psycho-social Health}

Global Citizenship Education or GCE means learning global issues and development issues on the basis of recognizing the interdependence of people living around the world. In the early days of GCE, delivering education and knowledge was limited to development aid, overseas service, and Official Development Goals (ODA) but it is being developed into global citizenship education. This refers to an education not only limited to the level of building knowledge but also an education that fosters an integrated, critical, and creative attitude through global perspective. 
Korea is the only country in the world that has evolved from being one of the poorest countries that depended on foreign aid to a 9th largest donor country in the world, and became a true advanced donor of the international community by becoming a 24th member country of the OECD Development Assistance Committee (DAC) in November 2009. Meanwhile, in 2000, UN gathered leaders from 189 countries to develop 8 MDGs (Millennium Development Goals), including the elimination of hunger around the world within 15 years. After that, centering around the UN, SDGs (Sustainable Development Goals) were presented to be implemented from 2016 to 2030. In other words, 17 common goals of humanity were declared to build a healthy global community based on human rights, respect for others, sharing, and consideration. This is consistent with the transformation from globalization of capitalist competition logic focused on the SDGs to 'globalization toward sustainable coexistence and sharing' and at the same time, this means a global effort to create a global community where people are psycho-socially healthy[7].

Such global citizenship educations are reported to be closely related to health behaviors, and the well-being created through the experience of recognizing the interdependence of people living around the world plays a role of providing sufficient emotional synchronization[8]. In this regard, the study of adolescents by László Brassai[9] and his colleagues found that a high level of personal well-being is significantly related to the promotion of healthy psycho-social activity. Therefore, advanced donor countries in Europe today perceive GCE as an education right that citizens should naturally have, not just to raise public awareness.

\subsection{Psycho-social Health of Adolescents}

Health behavior is a concept that encompasses all behaviors related to health by an individual and refers to health-promoting behaviors that in which human being actively responds to their own environment to move toward health[10]. Health-promoting behaviors have a very important impact on well-being of health levels and the promotion of growth development[11], and are also directly linked to subsequent health outcomes. Pender[10] attempted a specific and multidimensional approach to identify interactions between health-related variables[12], and a meta-analysis revealed that Pender's model of health-promoting behavior was valid, and it has been used in many studies related to health-promoting behaviors[13].

Recently, various domestic studies related to health have highlighted the importance of the psycho-social health condition perceived by individual as well as health-promoting behaviors. In particular, the psycho-social health during adolescence is an indicator of overall function of life, 
and is reported to have a significant relevance with subsequent health outcomes and health-promoting behaviors[4], and this is interpreted as due to the fact that morbidity rate of chronic diseases during adolescence is low, but can experience various daily health problems separately.

Meanwhile, some studies in Korea report the relevance of not only the personal internal variables of adolescents but also the various personal external variables including relationships. In other words, Kim Jong-Rim[3] emphasizes the importance of macroscopic and microscopic system of health during adolescence and verified the model that a support from parents and teachers influence health-promoting behaviors through internal health locus of control, self-esteem, and self-efficacy. In summary, it is considered that the psycho-social health interventions during adolescence taking an universal prevention approach for a wide range of subjects will be effective because it is very important to support adolescents for creating a psycho-socially healthy environment and educational approach, as it will have a positive and long-term effect on lifelong health-promoting behavior.

\subsection{GCE Module to Promote The Psycho-social Health of Adolescents}

As mentioned above, Global Citizenship Education or GCE means learning global issues and development issues on the basis of recognizing the interdependence of people living around the world. Therefore, GCE is a form of experiential education that participates in activities to meet human and community needs, with organizational opportunities intentionally designed to promote learning and psycho-social health development of adolescents[14] and is distinguished from general education due to the characteristic of reflection.

John Dewey said experience without the process of reflection is merely just an 'experience' that does not have 'educational meaning'[15], which means that when adolescents think deeply and reflect on learning experience of "GCE", their activities will result in educational achievement. Myers-Lipton also reported that adolescents who participate in GCE have increased their awareness of social responsibility and planned participation in civil action, which contributed to their psycho-social health[16]. In particular, tolerance and respect for others help develop self-awareness as adolescents become aware of social and personal diversity, which leads to the result of increasing self-efficacy by becoming confident about their activities, and such changes in self-efficacy ultimately help to promote psycho-social health[6].

The GCE is organized to promote learning on larger social issues behind the problems and demands of the international community that we are trying to solve to provide more in-depth 
understanding in terms of historical, cultural, economic, and political context of the issue[17]. And in this environment, adolescents can be synchronized to have psycho-social well-being, and the promotion of motivation leads to psycho-social health promotion. Therefore, this study maintained the form of group experiential learning activities in order to learn the meaning of psycho-social health based on mutual responsibility and mutual respect, and was designed to perform specific SDGs step by step[18].

\section{Method of Study}

\subsection{Research Analysis Framework}

This study configured the research analysis framework as shown in [Fig. 1] based on prior studies of Austin[19], Eyler \& Giles[6], and Myers-Lipton[16] that analyzed the GCE experience activities of adolescents.

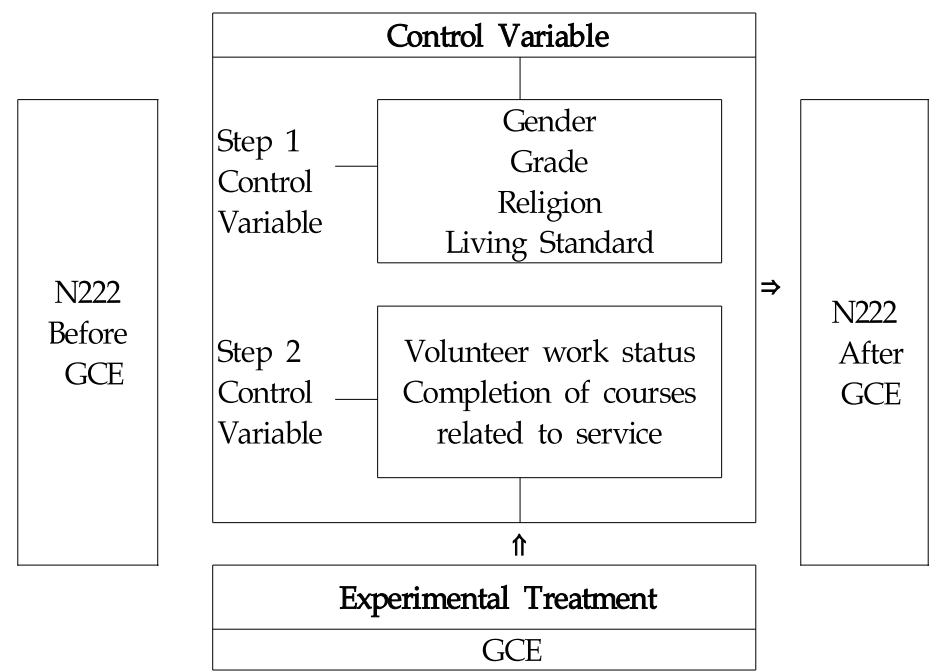

[Fig. 1] Analysis Framework of The Effect of GCE on The Psycho-social Health of Adolescents

\subsection{Research Subjects and Sampling}

The research subjects of this study were 238 male and female adolescents attending high schools in Seoul and Gyeonggi Province. However, only 222 participants were included in the final analysis, excluding 16 adolescents who did not fulfill the entire stage of global citizenship education. The survey period was from September to December 2017 for Group 1, and from March to June 2018 for Group 2, including overall period from recruiting the experimental 
group to post-result analysis. The reason why this study selected an adolescent sample as the study subject is as follows. First, students are in a situation where they cannot actively practice behaviors and habits related to maintaining psycho-social health because most of the education in this period is only focused on knowledge-oriented intellectual growth due to the fierce competition for university admission in future. Second, adolescents are preparing for the transition to adulthood in future, and lifestyle of this period influences not only the health in adulthood but also the health practice in macroscopic system such as local community in future.

\subsection{Measurement Tools}

Based on the prior studies of Rama[20], Eyler and Giles[6], and Austin[19], the results of "Global Citizenship Education (GCE)" are divided into two axes in this study. In other words, this study is divided into psycho-social health results where 5 dependent variables were divided and measured by self-efficacy and stress management for psychological health and personal relations, rest, and health care for social health. In terms of the measurement tool, this study used a profile by Jung Su-Jung[21] which was modified and supplemented for adolescents based on the health-promoting behavior profile by Kim Joon-Ho[22] which adapted and modified the Health Promoting Lifestyle Profile (HPLP) developed by Walker and his colleagues[12]. This profile consists of a total of 24 questions that measures the contents related to health care such as self-efficacy and personal relations, exercise and stress management, rest and sleep, regular meals, hygienic life, dietary control, and healthy diet and shows a .892 Cronbach's a coefficient.

\section{Study Results}

\subsection{General Characteristics of The Research Subjects}

The demographic and sociological characteristics of the adolescent participants of this study are shown in [Table 1]. 
[Table 1] General Characteristics of The Research Subjects http://dx.doi.org/10.14257/apjcri.2018.09.10

\begin{tabular}{|c|c|c|c|c|}
\hline \multicolumn{2}{|c|}{ Variable } & Frequency & Percentage & Total \\
\hline \multirow{2}{*}{ Gender } & Male & 84 & 37.84 & \multirow{2}{*}{$222(100.00 \%)$} \\
\hline & Female & 138 & 62.16 & \\
\hline \multirow{6}{*}{ Religion } & Christianity & 107 & 48.20 & \multirow{6}{*}{$222(100.00 \%)$} \\
\hline & Catholic & 40 & 18.02 & \\
\hline & Buddhism & 51 & 22.97 & \\
\hline & Confucianism & 2 & 0.90 & \\
\hline & No religion & 20 & 9.01 & \\
\hline & N/A or no response & 2 & 0.90 & \\
\hline \multirow{4}{*}{ Grade } & $1^{\text {st }}$ grade & 51 & 22.97 & \multirow{4}{*}{$222(100.00 \%)$} \\
\hline & $2^{\text {nd }}$ grade & 102 & 45.95 & \\
\hline & $3^{\text {rd }}$ grade & 68 & 30.63 & \\
\hline & No response & 1 & 0.45 & \\
\hline \multirow{6}{*}{$\begin{array}{l}\text { Social.economic } \\
\text { position }\end{array}$} & High & 1 & 0.45 & \multirow{6}{*}{$222(100.00 \%)$} \\
\hline & Above average & 73 & 32.88 & \\
\hline & Average & 120 & 54.05 & \\
\hline & Below average & 6 & 2.70 & \\
\hline & Low & 7 & 3.15 & \\
\hline & No response & 15 & 6.76 & \\
\hline Variable & Mean & $\begin{array}{l}\text { Standard } \\
\text { deviation }\end{array}$ & $\begin{array}{l}\text { Minimum } \\
\text { value }\end{array}$ & $\begin{array}{l}\text { Maximum } \\
\text { value }\end{array}$ \\
\hline Age & 17.03 & 1.86 & 16 & 19 \\
\hline
\end{tabular}

4.2 Before and After Analysis of GCE on The Psycho-social Health of Adolescents

This study performed a GCE before and after t-test in order to examine the effect of GCE on the psycho-social health of adolescents and the results are shown in [Table 2].

[Table 2] GCE Before and After t-test

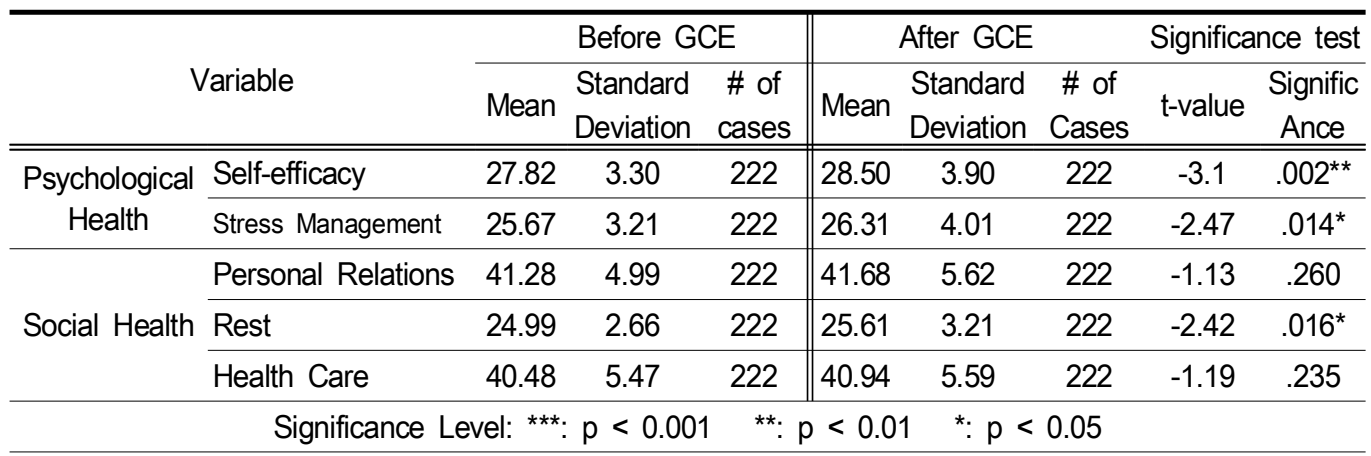


As shown in [Table 2], compared to before GCE, all of the participants showed high effectiveness in the areas of self-efficacy (.002) and stress management (.014) in terms of psychological health and rest (.016) in terms of social health after GCE participation. However, there were no significant differences in the means between before and after GCE in the areas related to personal relations and health care. This is considered to be partially consistent with the study results of Rama[20], Eyler \& Giles[6], and Austin[19] which led positive results for both psychological and social health.

In terms of this phenomenon, this study focuses on various mediator variables that could influence before and after results. Therefore, this study tried to measure these factors repeatedly by split-plot in order to control such influence as much as possible to understand the differences according to the characteristics between variable levels. The reason for this is to identify whether the "Global Citizenship Education (GCE)" effect has influenced the changes in each index by controlling the level of each factor pointed out as a between-subject factor through repeated measurements. Therefore, the effect of GCE, which is the treatment variable, was performed by within-subject analysis under controlling the mediator variables by comparison between before and after points of view, and through between-subject analysis, significance test was attempted through comparative analysis of differences between the levels of specific factors. This study verified whether the within-subject factor, or participation in GCE, the treatment effect influences the psycho-social health regardless of the level of a specific variable (main effect), and in addition, whether there is an interaction effect between the treatment factor and insertion factor.

As shown in [Table 3], the focus was on the following two study issues.

First, will there be a GCE effect regardless of the volunteer work experience of the participants? Second, will there be a GCE effect regardless of whether or not the participants have completed the courses related to service? The two questions were examined by using volunteer work status as the source for each dependent variable. In particular, if the sphericity assumption is not met, this study tried to analyze the within-subject effects through a well-known Greenhouse-Geisser verification method. As a result, in terms of the analysis of the effects within the participants of GCE, the effect of participating in GCE was found to be significant in self-efficacy (.001), stress management (.021), and rest (0.13). In addition, in relation to volunteering experience, the effects within the participants of GCE showed a significant difference in all variables of self-efficacy (.046), stress management (.002), personal relations (.000), and health care (.045), which confirmed that GCE has a positive effect on the psycho-social health promotion indicators of adolescents. As a result of analyzing data from 
various countries on the factors that predict subjective well-being, these results identified that human relationships during activity are an important predictor of subjective well-being, and are consistent with the study results of Hoyt[5], which claimed that positive relationships and sustainable bonds are the main sources of a healthy life.

[Table 3] GCE Effect Analysis According to The Volunteer Work Status

\begin{tabular}{|c|c|c|c|c|c|c|c|}
\hline \multirow{2}{*}{$\begin{array}{c}\text { Dependent } \\
\text { variable }\end{array}$} & \multirow{2}{*}{ Source } & \multicolumn{3}{|c|}{$\begin{array}{l}\text { Analysis of effects within } \\
\text { GCE participants }\end{array}$} & \multicolumn{3}{|c|}{ GCE } \\
\hline & & $\begin{array}{l}\text { Greenhouse- } \\
\text { Geisser F }\end{array}$ & $\begin{array}{l}\text { Degree of } \\
\text { freedom }\end{array}$ & Sig & $\mathrm{F}$ & $\begin{array}{l}\text { Degree of } \\
\text { freedom }\end{array}$ & Sig \\
\hline \multirow{3}{*}{ Self-efficacy } & Self-efficacy & 10.51 & 1 & $.001^{\star *}$ & & & \\
\hline & Self-efficacy * vol & .157 & 1 & .693 & & & \\
\hline & Volunteer work status & & & & 4.027 & 1 & $.046^{*}$ \\
\hline \multirow{3}{*}{$\begin{array}{l}\text { Stress } \\
\text { management }\end{array}$} & SM(Stress management) & 5.424 & 1 & $.021^{*}$ & & & \\
\hline & $\mathrm{SM} *$ vol & .265 & 1 & .607 & & & \\
\hline & Volunteer work status & & & & 10.033 & 1 & $.002^{* *}$ \\
\hline \multirow{3}{*}{$\begin{array}{l}\text { Personal } \\
\text { relations }\end{array}$} & PR(Personal relations) & 1.42 & 1 & 235 & & & \\
\hline & $\mathrm{PR} *$ vol & .565 & 1 & .496 & & & \\
\hline & Volunteer work status & & & & 12.985 & 1 & $.000^{\star * \star}$ \\
\hline \multirow{3}{*}{ Rest } & Rest'sleep & 6.291 & 1 & $.013^{*}$ & & & \\
\hline & Rest-sleep * vol & .571 & 1 & .451 & & & \\
\hline & volunteer work status & & & & .164 & 1 & .686 \\
\hline \multirow{3}{*}{ Health care } & Health care & 2.507 & 1 & .115 & & & \\
\hline & Health care ${ }^{*}$ vol & .279 & 1 & .598 & & & \\
\hline & Volunteer work status & & & & 4.074 & 1 & $.045^{*}$ \\
\hline \multicolumn{8}{|c|}{$\begin{array}{c}\text { Significance level: }{ }^{* *}: p<0.001 \quad{ }^{* *}: p<0.01 \quad{ }^{*}: p<0.05 \\
\text { Interaction within GCE participants: Dependent variable*vol(volunteer work status) } \\
\text { Effect analysis between GCE participants: Performed through comparison between } \\
\text { volunteer work status groups } \\
\text { If the sphericity assumption is not met, the within-subject effect are performed through } \\
\text { Greenhouse-Geisser verification }\end{array}$} \\
\hline
\end{tabular}

In particular, in the variables of stress management and personal relations, students who volunteered and participated in GCE showed a higher effect, which gives meaningful implications for developing a model of GCE for more systematic psycho-social health promotion in Korea.

In order to examine the effect of GCE according to the completion of courses related to service, the following analysis was conducted by using the status of completion of courses related to service as the source for each dependent variable as shown in [Table 4]. 
The Effect of Global Citizenship Education on The Psycho-social Health of Addescents

[Table 4] GCE Effect Analysis According to The Completion of Courses Related to Service

\begin{tabular}{|c|c|c|c|c|c|c|c|c|}
\hline & \multirow{2}{*}{$\begin{array}{c}\text { Dependent } \\
\text { variable }\end{array}$} & \multirow{2}{*}{ Source } & \multicolumn{3}{|c|}{$\begin{array}{l}\text { Effect analysis within GCE } \\
\text { participants }\end{array}$} & \multicolumn{3}{|c|}{$\begin{array}{l}\text { Effect analysis between } \\
\text { GCE participants }\end{array}$} \\
\hline & & & $\begin{array}{l}\text { Greenhouse- } \\
\text { Geisser F }\end{array}$ & $\begin{array}{l}\text { Degree of } \\
\text { freedom }\end{array}$ & Sig & $\mathrm{F}$ & $\begin{array}{l}\text { Degree of } \\
\text { freedom }\end{array}$ & Sig \\
\hline \multirow{5}{*}{$\begin{array}{l}\text { Psych } \\
\text { ologica } \\
\text { । } \\
\text { health }\end{array}$} & \multirow[b]{2}{*}{ Self-efficacy } & Self-efficacy & 10.944 & 1 & $.001^{* *}$ & \multirow[b]{2}{*}{2.972} & \multirow[b]{2}{*}{1} & \multirow[b]{2}{*}{.086} \\
\hline & & $\begin{array}{l}\text { Self-efficacy*service } \\
\text { course } \\
\text { Service course } \\
\text { completion }\end{array}$ & 1.033 & 1 & .310 & & & \\
\hline & \multirow{3}{*}{$\begin{array}{c}\text { Stress } \\
\text { management }\end{array}$} & Stress management & 8.128 & 1 & $.005^{\star *}$ & \multirow[b]{3}{*}{.196} & \multirow[b]{3}{*}{1} & \multirow[b]{3}{*}{.659} \\
\hline & & $\mathrm{SM}$ * service course & 1.539 & 1 & .216 & & & \\
\hline & & $\begin{array}{l}\text { Service } \\
\text { completion }\end{array}$ & & & & & & \\
\hline \multirow{6}{*}{$\begin{array}{l}\text { Social } \\
\text { health }\end{array}$} & \multirow{3}{*}{$\begin{array}{l}\text { Personal } \\
\text { relations }\end{array}$} & Personal relations & 5.923 & 1 & $.016^{*}$ & \multirow[b]{3}{*}{1.527} & \multirow[b]{3}{*}{1} & \multirow[b]{3}{*}{.218} \\
\hline & & $\mathrm{PR}$ * service course & .208 & 1 & .649 & & & \\
\hline & & $\begin{array}{l}\text { Service } \quad \text { course } \\
\text { completion }\end{array}$ & & & & & & \\
\hline & \multirow{3}{*}{ Rest } & Rest & 3.946 & 1 & $.048^{*}$ & \multirow[b]{3}{*}{1.147} & \multirow[b]{3}{*}{1} & \multirow[b]{3}{*}{.285} \\
\hline & & Restservice course & 2.659 & 1 & .104 & & & \\
\hline & & $\begin{array}{l}\text { Service course } \\
\text { completion }\end{array}$ & & & & & & \\
\hline \multicolumn{9}{|c|}{$\begin{array}{l}\text { Significance level: }{ }^{* *}: p<0.001 \quad * *: p<0.01 \quad{ }^{*}: p<0.05 \\
\text { raction within GCE participants: Dependent variable*completion of service related co } \\
\text { Effect analysis between GCE participants: Performed through comparison between } \\
\text { with(out) the completion of service related courses } \\
\text { If the sphericity assumption is not met, the within-subject effect are performed thro } \\
\text { Greenhouse-Geisser verification }\end{array}$} \\
\hline
\end{tabular}

Like the above, a well-known Greenhouse-Geisser verification was performed on the within-subject effects if the sphericity assumption is not met. As a result, significant results were found in all adolescents who participated in GCE regardless of the prior completion of courses related to service in self-efficacy (.001), stress management (.005), personal relations (.016), and rest (.048). In addition, there was no significant difference in the comparison between groups regardless of the completion of courses related to service, as shown in [Table 4]. These results indicate that there is no difference between the characteristics of the adolescent group that have completed the courses related to service in advance or that did not complete the courses, and imply that it is more effective to conduct GCE as an experiential learning model in conjunction with related volunteer activities rather than as a simple lecture-led education. 


\section{Conclusion and Suggestions}

The global citizenship education (GCE), which aims for 'sustainable coexistence where people live together' plays a role of providing a positive perception of yourself by building trust in humans along with the psycho-social well-being, which will remain as an internal working model that can affect the psycho-social health of an individual, and this study examines the effect of GCE on the psycho-social health of adolescents. As a result, the following implications of social welfare practice could be derived. First, in terms of the effect analysis within the GCE participants, the effect was significant in the areas of self-efficacy (.001), stress management (.021), and rest (.013). In addition, in terms of the effect between GCE participants related to volunteering experience, there was a significant difference in all variables of self-efficacy (.046), stress management (.002), personal relations (.000), and health care (.045), which confirmed that GCE has a positive effect on the psycho-social health promotion indicators of adolescents. In particular, in the variables of stress management and personal relations, students who volunteered and participated in GCE showed a higher effect, which gives meaningful implications for developing a model of GCE for the adolescents in Korea. Second, in order to examine the effect of GCE according to the completion of courses related to service, an analysis was conducted by using the status of completion of courses related to service as the source for each dependent variable. A well-known Greenhouse-Geisser verification was also performed on the within-subject effects if the sphericity assumption was not met. As a result, significant results were found in all adolescents who participated in GCE regardless of the prior completion of courses related to service in self-efficacy (.001), stress management (.005), personal relations (.016), and rest (.048). These results indicate once again that it is effective to intervene GCE as an experiential learning model in conjunction with related volunteer activities regardless of the characteristics between the adolescent group that completed the courses related to service in advance or the adolescent group that did not complete the courses. Third, adolescents can be synchronized to have a psycho-social sense of well-being when they deal with "actual" problems that are thought to be emotionally relevant or important, and the multidimensional elements needs to be included in the global citizenship education module conception in that the promotion of motivation leads to the promotion of the psycho-social health. 


\section{Acknowledgement}

This paper was supported by the Health Sciences for Specialization Project Fund of the Sahmyook University in 2018.

\section{References}

[1] Kim, Mi-Sun, Kang, Hyun-Sook, Cho, Kyoul-Ja, Factors Influencing Health-Promotion Behavior in Adolescents, Child Health Nursing Research, (2004), Vol.10, No.4, pp.496-503.

[2] Kim, Jin-Young, Ko, Young-Gun, The Relationship Between Positive Mental Health Type and Daily Physical Health in Adolescents. Korea Journal of Youth Studies, (2016), Vol.23, No.2, pp.25-45.

[3] Kim, Jong-Rim, A Structural Model between Micro System, Personal System, Health Promoting Behaviors of Late Adolescent: Verification on the Moderating Effect of Health Education, Kongju National University Master's degree paper, (2015)

[4] Ryff, C. D., Radler, B. T., \& Friedman, E. M., Persistent psychological well-being predicts improved self-rated health over 9-10 years: Longitudinal evidence from MIDUS, Health Psychology Open, (2015), Vol.2, No.2, pp.1-11.

[5] Hoyt, L. T., Chase-Lansdale, P. L., McDade, T. W., \& Adam, E. K., Positive youth, healthy adults: does positive well-being in adolescence predict better perceived health and fewer risky health behaviors in young adulthood?, Journal of Adolescent Health, (2012), Vol.50, No.1, pp.66-73.

[6] Eyler, J. \& Giles, D. E. Jr., Where's the learning in Service-Learning, San Francisco : Jossey-Bass, (2009)

[7] Korea International Cooperation Agency, www.koica.go.kr, (2018)

[8] Forgas, J. P. Belief and affect: On the mental pre-cursors of health-related cognition and behaviour, Journal of Health Psychology, (2013), Vol.18, No.1, pp.3-9.

[9] Brassai, L., Piko, B. F., \& Steger, M. F., A reason to stay healthy : The role of meaning in life in relation to physical activity and healthy eating among adolescents, Journal of Health Psychology, (2015), Vol.20, No.5, pp.473-482.

[10] Pender, N. J., Health Promotion in nursing parctice. 3rd Edition, Stanford; Appleton \& Lange, (1996)

[11] Ayres, C. G., Atkins, R., \& Mahat, G. Factors related to performance of health practices among Asian adolescents in the United States, Asian Nursing Research, (2010), Vol.4, No.2, pp.64-74.

[12] Walker, S. N., Kerr, M. J., Pender, N. J., \& Sechrist, K. R., A Spanish Language Version Of the Health-Promoting Lifestyle Profile, Nursing Research, (1990), Vol.39, No.5, pp.268-273.

[13] Gillis, A. J, Determinants of a health promoting lifestyle: an integrative review, Journal of Advanced Nursing, (1993), Vol.18, No.3, pp.345-353.

[14] Jacoby, B. (ed.), Service-Learning in Higher Education : Concepts and Practices, San Francisco, CA : 
Jossey-Bass Publishers, (2016)

[15] Kraft, R. \& Kielsmeier, J. (eds.), Experiential Learning in Schools and Higher Education, Dubuque : Kendall / Hunt Publishing Company, (2015)

[16] Myers-Lipton, S. J., Effect of a comprehensive service-learning program on college students' level of modern racism, Michigan Journal of Community Service-Learning, (2016), Vol.3, pp.44-54.

[17] Kendall, J. C., Combining service and learning : An Introduction. In J. C. Kendall(ed.). Combining Service and Learning : A Resource Book for Community and Public Service, 1. Raleigh, N.C.: National Society for Experiential Education, (2010)

[18] Cho, Misook, Understanding \& Practices of Official Development Assistance, Moonyea-Media, (2010)

[19] Austin, A.W, Higher education and the concept of Community, fifteenth David Dodds Heny Lecture, University of illinois at Urbana-Champagne, (2013)

[20] Rama, D. V., Ravenscroft, S. P., Wolcott, S. K., \& Zlotkowski, E., Service-Learning outcome : Guidelines for educators and researchers, Issues in Associating Education, (2015), Vol.15, No.4, pp.657-692.

[21] Jung, Su-Jung, The Effect of Smoking Cessation Education for Smoking Adolescents on Smoking Cessation and Health Promoting Behavior, Graduate School of Gachon University Master's degree paper, (2013)

[22] Kim, Joon-Ho, A Study on Factors Influencing Health Promoting Behavior in College Students, Graduate School of Inje University Master's degree paper, (2006) 